\title{
ANALYSIS OF DEBRIS FLOW BEHAVIOR USING AIRBORNE LIDAR AND IMAGE DATA
}

\author{
G. Kim ${ }^{\text {a }}$, C. Y. Yune ${ }^{\text {a }}$ J. Paik ${ }^{\text {a }}$, S. W. Lee ${ }^{\text {a, } *}$ \\ ${ }^{\text {a }}$ Dept. of Civil Engineering, Gangneung-Wonju National University, 7 Jukheon-gil, Gangneung, South Korea - \\ (ghkim, yune, paik, swl)@gwnu.ac.kr
}

Commission VIII, WG VIII/1

KEY WORDS: Debris Flow, LiDAR, Digital Surface Model, Geomorphologic Change

\begin{abstract}
:
The frequency of debris flow events caused by severe rainstorms has increased in Korea. LiDAR provides high-resolution topographical data that can represent the land surface more effectively than other methods. This study describes the analysis of geomorphologic changes using digital surface models derived from airborne LiDAR and aerial image data acquired before and after a debris flow event in the southern part of Seoul, South Korea in July 2011. During this event, 30 houses were buried, 116 houses were damaged, and 22 human casualties were reported. Longitudinal and cross-sectional profiles of the debris flow path reconstructed from digital surface models were used to analyze debris flow behaviors such as landslide initiation, transport, erosion, and deposition. LiDAR technology integrated with GIS is a very useful tool for understanding debris flow behavior.
\end{abstract}

\section{INTORODUTION}

Debris flows are rapidly flowing masses of water mixed with soil and gravel from landslides that are caused by typhoons or rainstorms. Korea's mountain-dominated topography (70\%) and seasonal heavy rain and typhoon events combine to cause landslides and large-scale debris flow events from June through August. These events often cause property damage and casualties that amount to $20 \%$ of total annual disaster fatalities (Lee et al., 2013). When Typhoon Rusa (2002) and Typhoon Maemi (2003) struck the Korean Peninsula, they caused typical debris flow damage, as shown in Figure 1. Local heavy rainfalls also caused debris flows in Gangwon-do areas in 2006 (Kim et al., 2011).

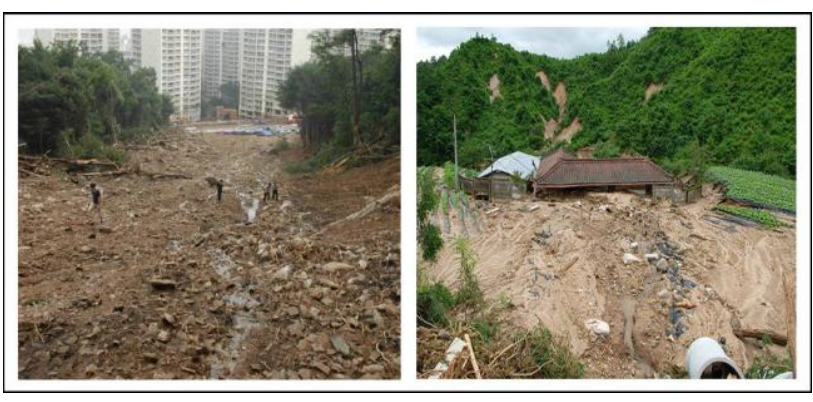

Figure 1. Examples of debris flow damage in South Korea

The Mt. Umyeon debris flow disaster that occurred in Seoul in 2011 resulted in casualties and property damage, and showed that debris flows can occur not only in mountainous areas, but also in urban environments. Given the hazards posed by highspeed debris flows in mountainous and urban areas, many researchers have sought to forecast landslide-induced debris flows to minimize damage (Ko et al., 2014).
To minimize casualties and property damage caused by debris flows, control structures are installed across potential debris flow paths and deposition areas, as shown in Figure 2 (Miyamoto, 2002). However, due to the high cost of installation, it is not possible to build control structures in all high-risk places. To enable the installation of control structures at bestsuited places for maximum efficacy, many studies have focused on establishing methods for precisely predicting debris flow path and scope of damage (Chun et al., 1997; Lee et al., 2011).

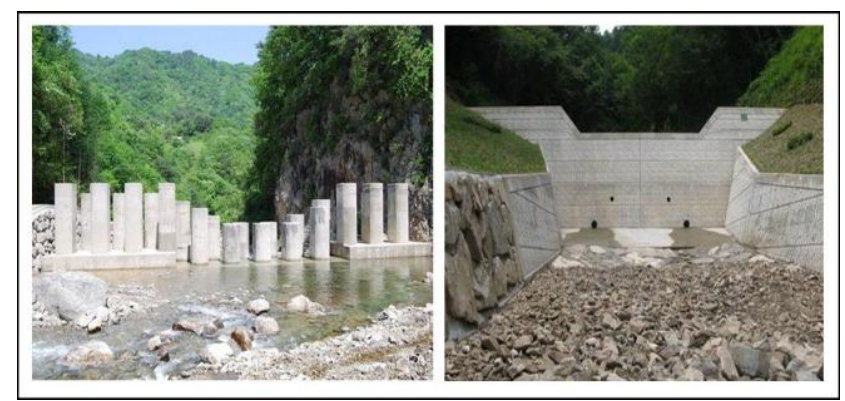

Figure 2. Control structures installed across debris flow paths

Owing to recent progress in photogrammetry and surveying technologies (e.g., LiDAR), it is now possible to produce centimeter-level ultra-high resolution digital elevation models (DEMs) that enable more accurate observations of geomorphologic changes. Many researchers have investigated methods for detecting large-scale landslides and debris flow areas with these technologies for the purpose of monitoring geomorphic changes, calculating the extent of changes and assessing debris flow behavior (McKean and Roering, 2004; Du and Teng, 2007; Tsutsui et al., 2007; Schelidl et al., 2008; Bull et al., 2010; Kim et al., 2014). However, because these studies examined LiDAR DEMs with relatively long intervals between acquisitions ( $\geq 5$ years), some natural topographic changes were

\footnotetext{
* Corresponding author
} 
missed. Moreover, the low spatial resolution of the LiDAR DEMs posed a limit to the observable size of debris flow induced geomorphic changes.

For a more accurate analysis of debris flow path and damage, the present study incorporated quantitative analysis of digital maps, aerial images, and high resolution LiDAR DEMs to delineate geomorphic and topographic changes induced by debris flow disaster.

\section{STUDY AREA AND DATA SET}

\subsection{Study area}

Mt. Umyeon, in Seoul, South Korea, was exposed to recordbreaking rainstorms in July 2011. Over four days, the rainfall totaled $595 \mathrm{~mm}$, an amount equaling approximately $41 \%$ of the average annual precipitation for the area. This event resulted in 16 deaths and flooding of residential areas.

Hydrological watershed analysis of Mt. Umyeon identified 13 areas and 31 watersheds affected by the debris flow event. A certain watershed was selected for geomorphic analyses based on the presence of clearly different topographic features before and after the debris flow(Figure 3).

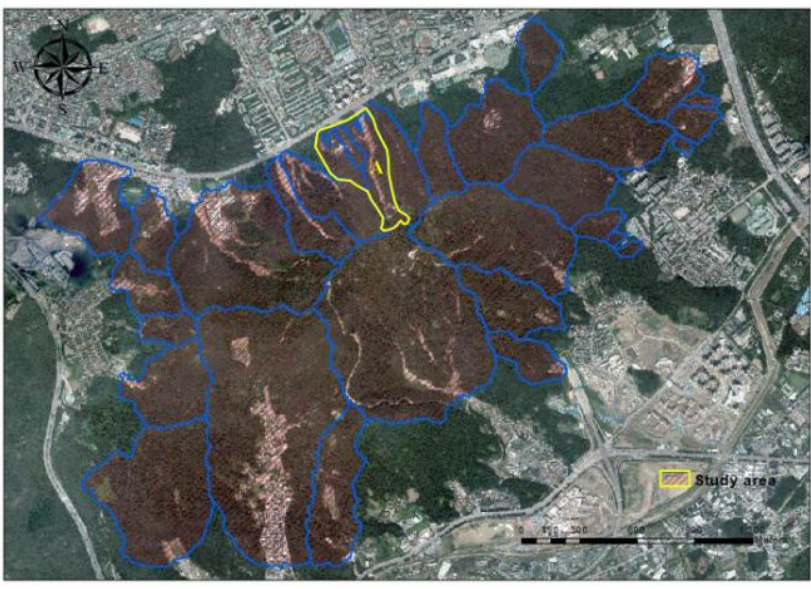

Figure 3. Aerial image of the study area, Mt. Umyeon, Seoul, South Korea, with watershed boundaries

\subsection{Data set}

Analyses were performed on aerial images and airborne LiDAR datasets obtained before and after the debris flow event as well as digital maps of the study area. All data were georeferenced to the GRS80 ellipsoid with central projection origin at $38^{\circ} \mathrm{N} \mathrm{x}$ $127^{\circ} \mathrm{E}$ (reference value of the projection origin was easting 200,000 and northing 600,000). Figure 4 shows the aerial photos acquired before and immediately after the debris flow event. Both images have a spatial resolution of $25 \mathrm{~cm}$.

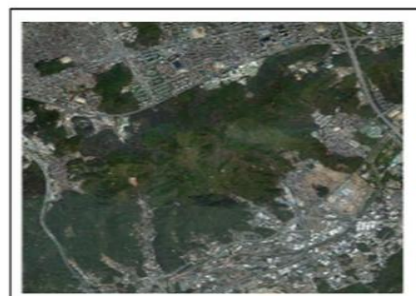

(a) August 2009

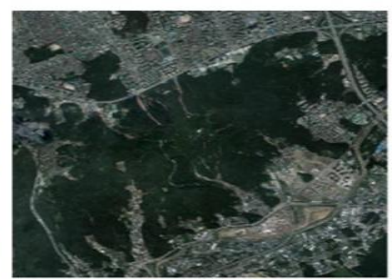

(b) August 2011
Figure 4. Aerial images before and after the debris flow damage
Digital maps of Mt. Umyeon and surrounding areas were selected at a scale of 1/5,000 for this study, as shown in Figure 5. Analysis of the digital maps found that six indices could be used at this scale. Digital maps at a scale of $1 / 1,000$ were available but could not be used because their coverage did not include the forest of Mt. Umyeon.

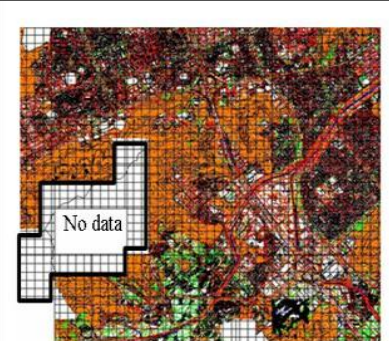

(a) $1 / 1,000$

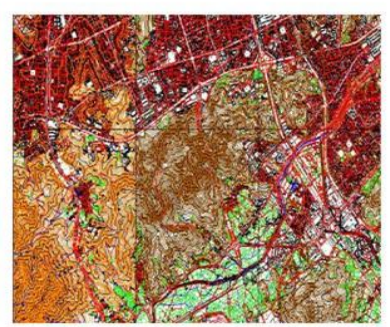

(b) $1 / 5,000$
Figure 5. Digital maps of the disaster area

High-resolution DEMs of the disaster area were generated from airborne LiDAR data acquired at a spatial resolution of $56 \mathrm{~cm}$ before and after the debris flow event. The DEMs were then interpolated to $1 \mathrm{~m}$ resolution, as shown in Figure 6.

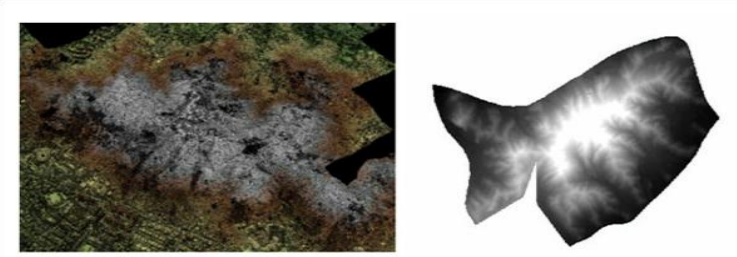

(a) LiDAR point cloud and DEM(August 2009)
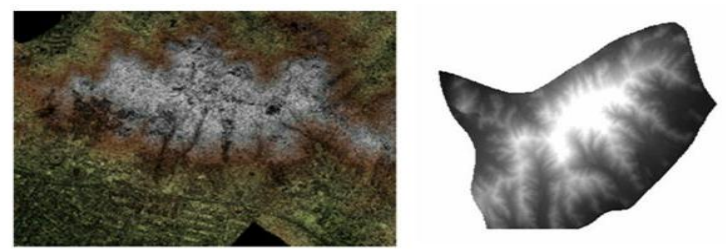

(b) LiDAR point cloud and DEM(August 2011)

Figure 6. Airborne LiDAR data obtained before and after the debris flow event

\section{DEBRIS FLOW ANALYSIS}

\subsection{Analysis method}

A comprehensive analysis of LiDAR DEMs, aerial images, and digital maps of Mt. Umyeon was performed to make geomorphic comparisons of the study area before and after the debris flow event. The landslide and debris flow behaviors were assessed for the watershed that incurred the most damage. To quantify the geomorphic changes induced by the event, the flow paths before and after the event were determined (Figure 7), and longitudinal and cross-sectional profiles were extracted (Figure 8). The longitudinal run of the debris flow path was observed at $20 \mathrm{~m}$ intervals from the initiation point to the watershed exit, and the cross-sectional features were observed at $1 \mathrm{~m}$ intervals 
across the width of the watershed after obtaining the crosssection orthogonal to the flow path for each profile point.

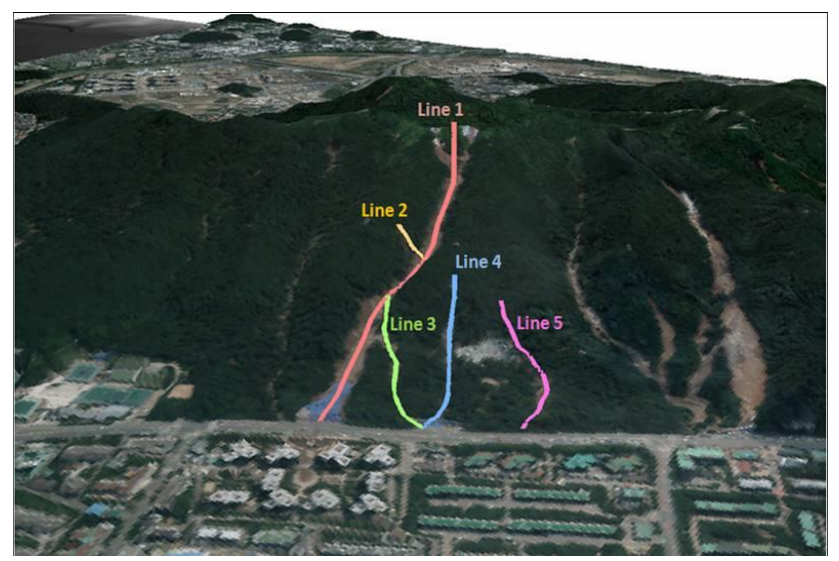

Figure 7. 3D schema of the flow path before and after the event

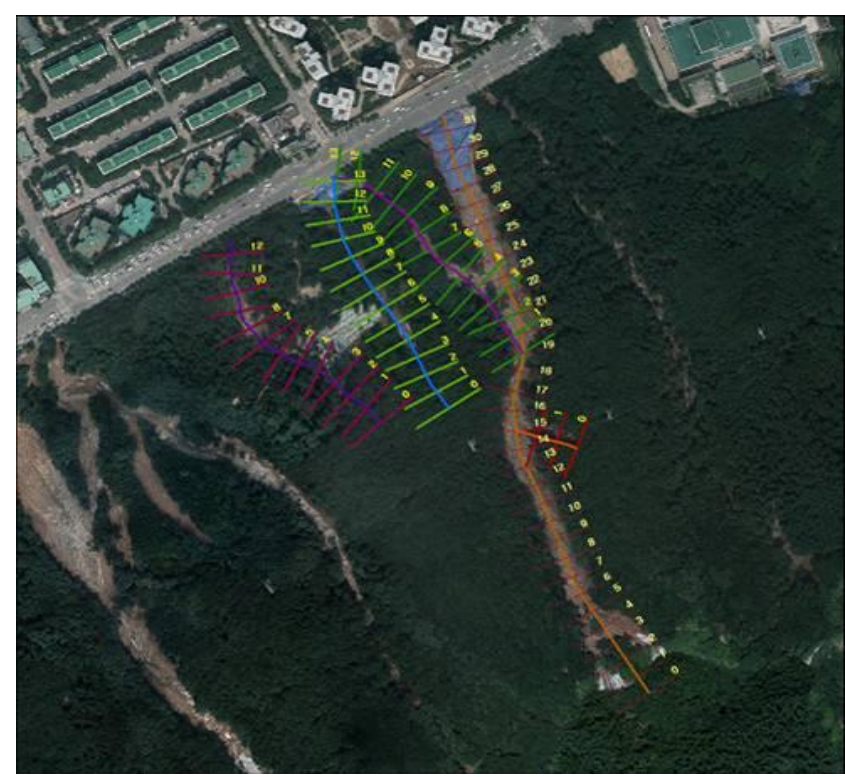

Figure 8. Extraction of longitudinal and cross-sectional profiles

\subsection{Analysis results}

The longitudinal and cross-sectional profiles extracted from the DEM of the watershed revealed clearly different geomorphic details before and after the debris flow. Geomorphic changes were quantified by determining flow and sub-flow directions, erosion and deposition areas.

As shown in Figure 9, Watershed A incurred four large-scale landslides, thus inducing a large-scale debris flow. Along the path of the main debris flow, small-scale debris flows were found to join the main path on Line 1 and Line 5. In the case of Line 1, greater damage was incurred in comparison to other debris flow paths because most of the soil and gravel traveled within the water flow and, without being deposited, crossed the road and followed the course into the residential area. The combined deposition of Line 1 and Line 2 was estimated by longitudinal and cross-sectional analyses to be $13,500 \mathrm{~m}^{3}$ and that of Line 3 and Line 4 was estimated to be $4,000 \mathrm{~m}^{3}$. Line 5 was estimated to have deposited the majority of its sediment near the watershed exit.
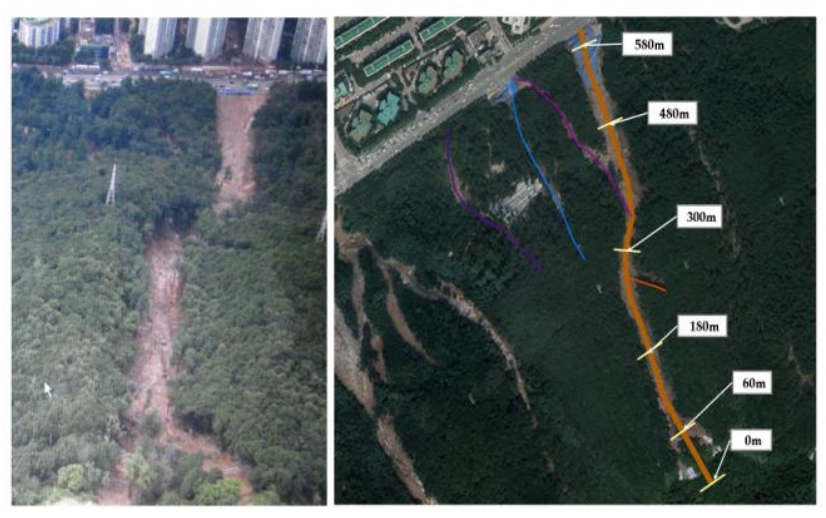

(a) Longitudinal and cross-sectional profiles

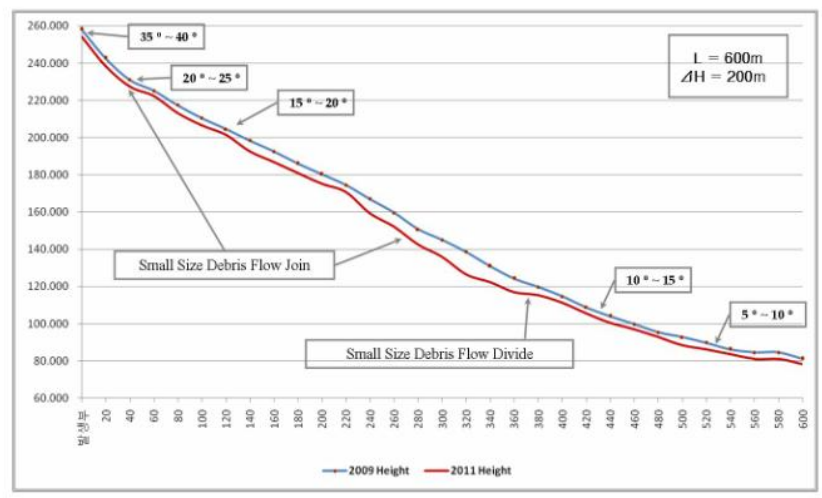

(b) Longitudinal analysis

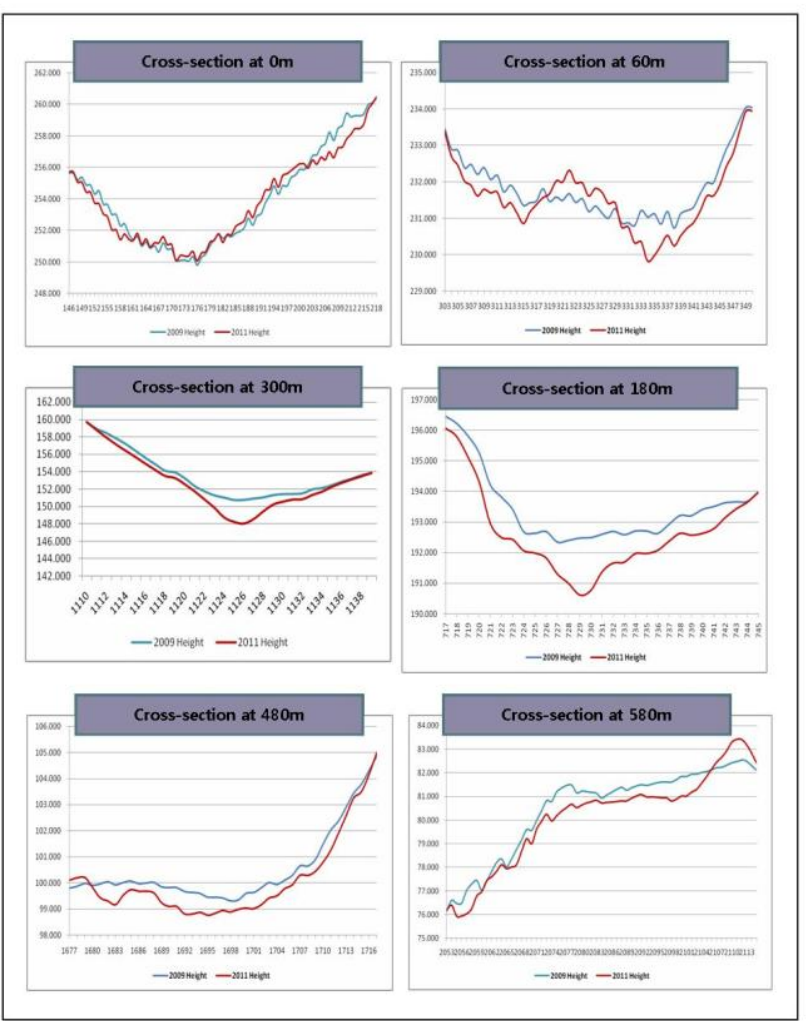

(c) Cross-sectional analysis 


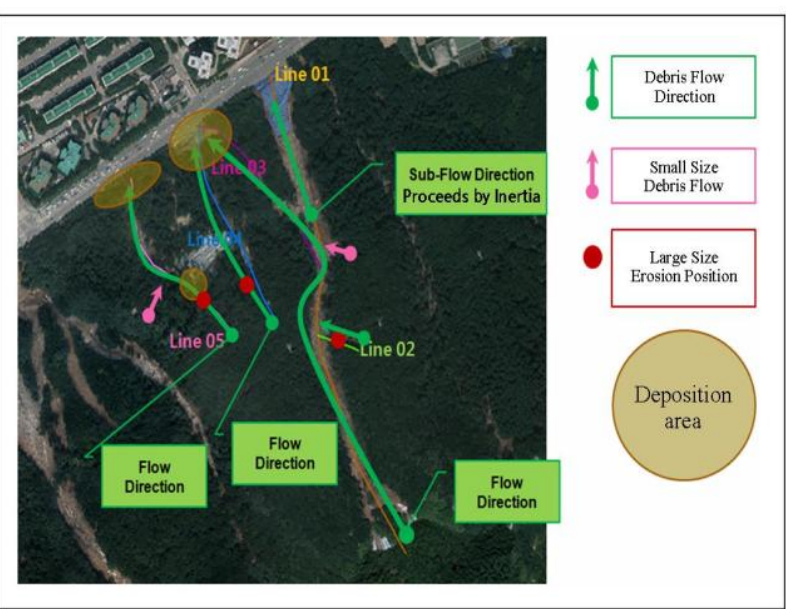

(d) Overall assessment

Figure 9. Assessment of the debris flow paths

\section{CONCLUSIONS}

This study presented methodology for analysis of debris flow using DEMs derived from airborne LiDAR data acquired before and after the debris flow event. The following summarizes the conclusions drawn from the results.

First, quantitative and efficient analysis of debris flow characteristics can be implemented using an airborne LiDAR DEM. This method produces volumetric estimations of debris flow at higher accuracy than those derived via surface surveying. Second, the proposed methodology of extracting longitudinal and cross-sectional profiles of a debris flow using a LiDAR DEM enabled an overall assessment of the debris flow, from its initiation position through its flow path to its final deposition position. The findings of this study confirmed that an overall quantitative assessment of debris flow is possible.

Third, the scope of damage in the affected watersheds can be calculated during debris flow behavior assessment by comparing geomorphic features present before and after the event and subsequently quantifying the geomorphologic changes caused by the debris flow event.

The methods proposed in this study are recommended for efficient estimation of scale and characterization of debris flow for a large-scale disaster area with limited accessibility. The digital maps, aerial images, and LiDAR DEM data and associated methodologies presented here serve as complimentary tools to be used alongside field survey data when analyzing debris flow behaviors and characteristics.

\section{ACKNOWLEDGEMENTS}

This research was supported by the Public Welfare \& Safety Research Program through the National Research Foundation of Korea (NRF) funded by the Ministry of Science, ICT \& Future Planning (Grant No. 2012M3A2A1050979).

\section{REFERENCES}

Bull, J.M., Miller, H. and Gravley, D.M., 2010. Assessing debris flow using LiDAR differencing: 18 May 2005 Matata event, New Zealand. Geomorphology, 124(1-2), pp. 75-84.
Chun, K., Kim, M., Park, W. and Ezaki, T., 1997. Characteristics of channel bed and woody debris on mountainous stream, Journal of Korean Forest Society, 86(1), pp. 69-79.

Du, J.C. and Teng, H.C., 2007. 3D laser scanning and GPS technology for landslide earthwork volume estimation. Automation in Construction, 16(5), pp. 657-663.

Kim, G.N., 2011. A Basic Study on the Development of the Guidelines on Setting Debris Flow Hazards, Research Institute for Gangwon, Korea.

Kim, H., Lee, S.W., Yune, C.Y., and Kim, G., 2014. Volume Estimation of Small Scale Debris Flows Based on Observations of Topographic changes Using Airborne LiDAR DEMs, Journal of Mountain Science, 11(3), pp. 578-591.

Ko, S.M., Lee, S.W., Yune, C.Y. and Kim, G., 2014. Topographic analysis of landslides in Umyeonsan, Journal of the Korean Society of Surveying, Geodesy, Photogrammetry and Cartography, 32(1), pp. 55-62.

Lee, C.W., Woo, C.S. and Youn, H.J., 2011. Analysis of debris flow hazard by the optimal parameters extraction of random walk model, Journal of Korean Forest Society, 100(4), pp. 664671.

Lee, S.W., Lee, T.O., Jeon, C.G., Choi, C.R. and Yoo, N.J., 2013. Development of Mountain Road Alignment/Drainage Design and Disaster Prediction Map, Land Transport R\&D Report, Korea Agency for Infrastructure Technology Advancement, Korea.

McKean, J. and Roering, J., 2004. Objective landslide detection and surface morphology mapping using high-resolution airborne laser altimetry. Geomorphology, 57(3-4), pp. 331-351.

Miyamoto, M., 2002. Two dimension numerical simulation of landslide mass movement, Journal of the Japan Society of Erosion Control Engineering, 55(2), pp. 5-13.

Scheidl, C., Rickenmann, D. and Chiari, M., 2008. The use of airborne LiDAR data for the analysis of debris flow events in Switzerland. Natural Hazards and Earth System Sciences, 8(5), pp. 1113-1127.

Tsutsui, K., Rokugawa, S. and Nakagawa, H., 2007. Detection and volume estimation of large-scale landslides based on elevation-change analysis using DEMs extracted from highresolution satellite stereo imagery. IEEE Transactions on Geoscience and Remote Sensing, 45(6), pp. 1681-1696. 